\title{
Vivências e memórias entre a Escola Monsenhor Lopes e a Comunidade Forte
}

\author{
Suzana Gomes Lopes ${ }^{\mathrm{III}}$ \\ Alexandre Leite dos Santos Silva ${ }^{\text {III,IV }}$ \\ Caroline Lucena de Sousa ${ }^{\mathrm{v}, \mathrm{VI}}$
}

https://doi.org/10.24109/2176-6681.rbep.102.i260.4044

\footnotetext{
Universidade Federal do Piauí (UFPI). Picos, Piauí, Brasil.E-mail: <sglopes@ ufpi.edu.br $>$; <https://orcid. org/0000-0001-9071-9585>.

II Doutora em Biotecnologia pela Rede Nordeste de Biotecnologia (Renorbio) Universidade Federal do Maranhão (UFMA). São Luís, Maranhão. Brasil.

III Universidade Federal do Piauí (UFPI). Picos, Piauí, Brasil. E-mail: <alexandreleite@ ufpi.edu.br >; <https://orcid. org/0000-0002-8239-9240>.

Iv Doutor em Educação pela Universidade Federal de Uberlândia (UFU). Uberlândia, Minas Gerais, Brasil.

v Universidade Federal do Piauí (UFPI). Picos, Piauí, Brasil. E-mail: $<$ karollucena1@hotmail. com>; <https://orcid. org/0000-0002-2524-0620>.

vI Graduada em Licenciatura em Educação do Campo/ Ciências da Natureza pela Universidade Federal do Piauí (UFPI). Picos, Piauí, Brasil.
}

\section{Resumo}

O objetivo deste trabalho é mostrar a história da Escola Monsenhor Lopes e sua relação com a Comunidade Forte. Para isso, as vivências e memórias dessa história foram obtidas e registradas mediante documentos e entrevistas. O quadro teórico baseou-se em autores que trataram da história das instituições escolares e da Educação do Campo. A análise dos dados utilizou categorias que apresentam cronologicamente o desenvolvimento dos fatos. Os resultados da pesquisa revelaram que a escola foi importante para a escolarização da população local, constatando-se, também, sua interação com outras instituições. Contraditoriamente, ao longo do tempo, a escola tem contribuído tanto para a permanência dos sujeitos no campo como para o esvaziamento deste. Por fim, afirma-se que a Escola Monsenhor Lopes tem colaborado para o desenvolvimento local.

Palavras-chave: comunidade; educação no campo; memória histórica. 


\section{Abstract \\ Experiences and memories between the Monsenhor Lopes School and the Forte Community}

This paper explores the history of Monsenhor Lopes School and its relationship with the Forte Community. Thus, the experiences and memories that write this story were gathered and recorded through documents and interviews. The theoretical framework is based on authors who dealt with the history of school institutions and rural education. Data analysis considered categories that presented issues chronologically. Results showed that the school was instrumental for the schooling of the local population, also verifying its interaction with other institutions. Contradictorily, the school has overtime contributed both to the permanence of the subjects in the rural community and to their exodus. Finally, it is found that the Monsenhor Lopes School has contributed for local development.

Keywords: community; historical memory; rural education.

\section{Resumen \\ Vivencias y memorias entre la Escuela Monsenhor Lopes y la Comunidad Forte}

El objetivo de este trabajo es mostrar la historia de la Escuela Monsenhor Lopes y su relación con la Comunidad Forte. Para ello, se obtuvieron y registraron las vivencias y memorias de esta historia por medio de documentos y entrevistas. El marco teórico se basó en autores que abordaron la historia de las instituciones escolares y de la educación rural. El análisis de los datos utilizó categorías que presentan cronológicamente el desarrollo de los hechos. Los resultados de la investigación revelaron que la escuela fue importante para la educación de la población local, así como su interacción con otras instituciones. Contradictoriamente, con el tiempo, la escuela ha contribuido tanto a la permanencia de los sujetos en la comunidad rural como a su vaciamiento. Finalmente, se dice que la Escuela Monsenhor Lopes ha contribuido al desarrollo local.

Palabras clave: comunidad; educación rural; memoria histórica. 


\section{Introdução}

As instituições escolares podem ser definidas como unidades de ação sociais constituídas como "um conjunto de agentes que travam relações entre si e com a sociedade a que servem" (Saviani, 2013, p. 35). Portanto, uma escola não atinge apenas os alunos no processo de escolarização, mas também a comunidade ${ }^{1}$ na qual está inserida. As instituições escolares estão imbricadas com outras instituições da sociedade, como a Igreja, o Estado e a família. Por isso, é possível distinguir as instituições que fazem o trabalho educativo primário, o qual, guiado por uma pedagogia implícita, educa de forma espontânea, assistemática e informal, como a família, os sindicatos, as igrejas, os partidos, as associações etc., das que fazem o trabalho educativo secundário, com uma pedagogia explícita, tais quais as igrejas e o Estado, por meio das instituições escolares.

As pesquisas sobre a história das instituições escolares são muito importantes por vários motivos. Conforme Gatti Júnior e Gatti (2015), alguns desses motivos são: 1) para melhor compreender a relação entre o Estado e a sociedade na formação do homem, sendo a escola portadora dos elementos simbólicos e materiais que representam essa relação; 2) a história das escolas é imbuída de expectativas institucionais que nortearam a formação de pessoas e gerações, dentro de contextos socioculturais; e 3) as escolas são locais de conflitos ideológicos que representam tensões maiores presentes na sociedade. Assim, o entendimento desses conflitos que se sucedem dialeticamente e historicamente, no recorte dos tempos e dos espaços escolares, permite aprofundar a compreensão da realidade mais ampla, inclusive as ações dos sujeitos individuais e coletivos.

Além disso, estudar a história das instituições escolares é fazer um percurso no tempo e no espaço a fim de captar os fatores, as relações, os determinantes e as contradições da sociedade em busca da satisfação das necessidades, quer estas representem os interesses das classes dominantes, quer os interesses da classe trabalhadora (Saviani, 2013).

Nessa direção, esta pesquisa tem como objetivo, com base no estudo da história da Escola Municipal Monsenhor Lopes, na área rural do município de Inhuma/Piauí (PI), compreender a relação dessa escola com a Comunidade Forte, da qual faz parte, no período entre 1972, ano de sua criação, e 2018, quando os dados foram coletados. O problema que norteou este trabalho foi: como foi/tem sido a relação entre a Escola Monsenhor

O conceito de comunidade empregado neste estudo se baseia em Teixeira (2010). De acordo com esse autor, a comunidade escolar é composta pelos segmentos que participam, de alguma maneira, do processo educativo desenvolvido em uma escola.

\section{Lopes e a Comunidade Forte?}

O recorte da investigação abordou a relação da instituição escolar com a Comunidade Forte, mas reconhecemos também que a escola atende a outras comunidades circunvizinhas, como Vereda, Vereda do Forte, Saquinho, Barreiro Branco, Cocos, Barrocão, Atrás da Serra, Canto, Pitanguá, Forte e Cabeceira do Forte. 
Por meio de uma breve revisão de literatura, foi possível identificar alguns trabalhos que também resgataram as memórias de escolas municipais da área rural. Por exemplo, Beck (2015) fez um estudo historiográfico de uma escola municipal da área rural do município de Tangará da Serra, estado de Mato Grosso, com o objetivo de analisar as representações de escolarização da infância na cultura escolar. Para tal fim, respaldou-se teoricamente em diversos autores relacionados à história cultural e utilizou como fontes documentos e história oral. Quanto a esta última, entrevistou uma professora, ex-alunos e seus pais com referência ao período entre 1965 e 1983. O estudo apontou que o desenvolvimento da educação escolar no espaço rural considerado ocorreu devido ao envolvimento e ao interesse das famílias migrantes em busca de melhores condições de vida.

Também Jesus (2016) fez uma reconstrução da história e da memória de uma escola rural do município de Rio Verde, estado de Goiás, no intervalo entre 1997 e 2015. Procurou entender como se deu o surgimento da escola e qual sua relevância para a comunidade a que atende. Para isso, recorreu à história cultural e à história oral. Os dados foram coletados de narrativas de funcionários e ex-alunos. Os resultados mostraram que a escola teve um papel fundamental na vida das crianças da comunidade.

Andrade e Arnaut de Toledo (2017) realizaram uma pesquisa sobre a instalação de uma escola do Povoado de Xaxim, área rural do município de Toledo, no estado do Paraná. O estudo, com base na análise documental, cobriu a história da instituição no período de 1950 a 1960. Entre os achados, está a conclusão de que a implantação da escola teve uma finalidade não apenas educativa para a classe trabalhadora a que atendeu, mas também cívica, patriótica e econômica, correspondendo ao projeto de nacionalização no oeste paranaense.

Este trabalho, assim como os de Beck (2015) e Jesus (2016), recorreu tanto a documentos como a fontes orais e procurou reconstruir a história de uma escola municipal e sua relação com a comunidade rural a que atende. Entretanto, aproxima-se teoricamente de Andrade e Arnaut de Toledo (2017), já que não se limitou aos pressupostos teóricos da história cultural. Outro diferencial deste estudo está na busca da reconstrução histórica de uma escola de uma comunidade rural de um município do semiárido piauiense, que possui um contexto político e socioeconômico característico.

Dito isso, o artigo está segmentado em quatro partes. Primeiramente, é apresentada a fundamentação teórica da pesquisa, apoiada em autores que tratam da história das instituições escolares e da Educação do Campo. No segundo momento, é exposto o percurso metodológico. Depois, seguem-se os resultados e as discussões. Por fim, o texto traz as considerações finais.

\section{História das instituições escolares}

As pesquisas sobre a história das instituições escolares no Brasil remontam à década de 1950 (Gatti Júnior; Gatti, 2015) e contemplam 
perspectivas teórico-metodológicas diversas, num pluralismo epistemológico e temático perpassado por orientações marxistas, idealistas, positivistas, estruturalistas e culturalistas (Buffa; Nosella, 2006).

Segundo Saviani (2013), a história da escola não é construída porque isso já se deu no tempo. Logo, cabe ao pesquisador reconstruir o conhecimento dessa história. Para tanto, são necessárias fontes confiáveis de dados. De acordo com Libanio e Nogueira (2014), o primeiro passo na pesquisa de campo deve ser procurar por registros da história da instituição; depois, buscar documentos (escritos, pictóricos, arquitetônicos etc.) que dão testemunho dessa história.

Neste sentido, consideram-se fontes históricas escolares a serem sistematizadas, interpretadas e descritas os seguintes elementos: aspectos de identidade da criação da Instituição Escolar, quais sejam, documentos administrativos comprobatórios como registros de matrícula, atas de reuniões, atas de posse, de exames, boletins de frequência e de avaliações de alunos, diários de classe, livro de assinaturas de ponto, currículos de professores e funcionários, atos disciplinares, matriz curricular do curso, boletim de frequência e nota de alunos, número inicial de turmas, caracterização do perfil socioeconômico dos/as estudantes, entre outros. (Libanio; Nogueira, 2014, p. 6).

Esses documentos geralmente são encontrados em locais como acervos da própria instituição escolar, biblioteca municipal, câmara de vereadores, jornal local etc. Na sequência, para preencher as lacunas de dados não obtidos documentalmente, pode-se recorrer, por meio de entrevistas, a "profissionais que preferencialmente tenham vivido o processo institucional à época delimitada" (Libanio; Nogueira, 2014). Além destes, são importantes como fonte de dados alunos, ex-alunos e pais, que podem contribuir para a análise do perfil institucional e para a discussão sobre a relevância social da instituição (Saviani, 2013).

Ademais, durante a pesquisa devem ser consideradas as condições sociais dos contextos histórico-geográficos nos quais as escolas surgiram, relacionando o micro com o macro, o singular com o universal (Sanfelice, 2009). Isso requer conhecimentos acerca de história geral, nacional e local, o que implica amplos estudos bibliográficos.

Após a constituição do corpus, ou seja, do conjunto do material coletado na forma de documentos, transcrições de entrevistas, registros fotográficos, entre outros, é necessário que haja uma análise à base de categorias que contribuam para responder à problemática levantada. Gatti Júnior (2007) expõe algumas categorias, conforme mostra o Quadro 1. 


\section{Quadro 1 - Categorias de análise no estudo historiográfico das instituições escolares}

\section{Magalhães (1998)} Buffa e Nosella (2005)

- Espaço (local/lugar, edifício, topografia).

- Tempo (calendário, horário, agenda antropológica).

- Currículo (conjunto das matérias lecionadas, métodos, tempos etc., ou racionalidade da prática).

- Modelo pedagógico (construção de uma racionalidade complexa que articule a lógica estruturante interna com as categorias externas que a constituem - tempo, lugar e ação).

- Professores (recrutamento, profissionalização, formação, organização, mobilização, história de vida, itinerários, expectativas, decisões, compensações)

- Manuais escolares.

- Públicos (cultura, forma de estimulação e resistências).

- Dimensões (níveis de apropriação, transferências da cultura escolar, escolarização, alfabetização, destinos de vida).
- $\quad$ Origem, criação, construção e instalação.

- Prédio (projeto, implantação, estilo e organização do espaço).

- Mestres e funcionários (perfil).

- $\quad$ Clientela (alunos, ex-alunos).

- $\quad$ Saber (conteúdos escolares).

- $\quad$ Evolução.

- Vida (cultura escolar: prédio, alunos, professores e administradores, normas).

- Organização e vida política, econômica e cultural da cidade.

- O destino profissional dos atores da instituição escolar.

Fonte: Elaboração própria baseada em Gatti Júnior (2007).

Essas categorias, entre outras, contribuem para a estruturação de roteiros de trabalho que nortearão os processos investigativos, de acordo com o objetivo de:

[...] dar conta dos vários sujeitos envolvidos no processo educativo, investigando aquilo que se passa no interior das escolas, gerando um conhecimento mais aprofundado destes espaços sociais destinados aos processos de ensino e de aprendizagem, por meio da busca da apreensão daqueles elementos que conferem identidade à instituição educacional, ou seja, daquilo que lhe confere um sentido único no cenário social do qual fez ou ainda faz parte, mesmo que ela tenha se transformado no decorrer dos tempos. (Gatti Júnior, 2007, p. 184).

Desse modo, percebe-se em tal objetivo da pesquisa em história das instituições escolares um potencial para desvelar não apenas aspectos da escola, mas do cenário social e dinâmico do qual ela faz parte. Nesse 
sentido, quando o cenário é a área rural, é necessário que se considere a relação da escola com os paradigmas educacionais da Educação Rural e da Educação do Campo.

\section{Educação Rural e Educação do Campo}

A Educação Rural é o paradigma historicamente hegemônico que permeia a maioria das escolas da área rural, construído por interesses alheios ao trabalhador do campo (Ribeiro, 2013). Caracteriza-se por ter uma perspectiva urbanocêntrica, isto é, que propõe uma escolarização para o camponês nos moldes das escolas urbanas. E assim porque concebe a vida urbana como mais evoluída que a rural. Então, vê como papel da escola tirar o homem do campo da situação de atraso, desconsiderando os saberes e os valores da população camponesa e não contribuindo para a permanência do homem na área rural (Fernandes, 2008).

A Educação do Campo é vista como um paradigma educacional contrahegemônico que ganhou força desde o fim da década de 1990 (Kolling; Nery; Molina, 1999). Surgiu como resultado de lutas sociais por escolas do e no campo, dentro de um projeto de educação elaborado pela própria população camponesa, e da confluência de diversos referenciais pedagógicos: a pedagogia do oprimido, a pedagogia do movimento e a pedagogia socialista (Caldart, 2011). Os fundamentos da Educação do Campo, segundo o Grupo Permanente de Trabalho em Educação do Campo, estão na noção de complementaridade entre campo e cidade e no fortalecimento da identidade campesina, de forma a propiciar a permanência do homem no campo e o desenvolvimento sustentável deste (Brasil. MEC, 2003, 2007; Molina; Jesus, 2004; Caldart, 2012). A Educação do Campo está ancorada na Lei de Diretrizes e Bases da Educação Nacional (Lei n ${ }^{\circ}$ 9.394, de 20 de dezembro de 1996) , nas Diretrizes Operacionais para a Educação Básica das Escolas do Campo (Brasil. MEC. CNE. Ceb, 2002) e nas Diretrizes Curriculares Nacionais para a Educação Básica (Brasil. MEC, 2013).

Além disso, a Educação do Campo é norteada por princípios como: 1) a educação de qualidade como direito da população camponesa, com respeito a sua cultura, seus valores e conhecimentos; 2) a educação construída com respeito a organizações comunitárias e seus saberes; 3) a educação organizada no espaço camponês; 4) a educação produtora de uma cultura mediada pelo trabalho na terra e para a terra; 5) a educação para o desenvolvimento sustentável; e 6) a educação contextualizada, com respeito à heterogeneidade dos povos do campo (Brasil. MEC. Secadi, 2007).

\section{Percurso metodológico}

Os dados do estudo, coletados ao longo do ano de 2018, foram obtidos em entrevistas semiestruturadas e documentos oficiais escritos, materiais escolares e fotografias de acervos públicos e privados. A pesquisa 
da história de instituições escolares pode sofrer limitação quando a quantidade e a qualidade dos documentos não permitem preencher todas as lacunas temporais nem dar subsídio para a compreensão de todas as práticas institucionais (Saviani, 2013), o que ocorreu com a presente investigação. Por isso, a utilização das entrevistas semiestruturadas foi prevista desde o início da elaboração do trabalho, em virtude da possibilidade de vazios documentais referentes à história da escola (Meihy; Ribeiro, 2011).

Houve a participação de diversos interlocutores, que, por motivos éticos, não terão a identidade revelada. Esse anonimato se justifica por consistir em uma forma de proteger os interlocutores de possíveis problemas, como perseguição política, ou evitar constrangimentos envolvendo terceiros (Meihy; Ribeiro, 2011). Por isso, os atores escolares e comunitários que foram entrevistados e contribuíram para a pesquisa estão identificados pela abreviatura de seus nomes. Cinco interlocutores foram selecionados:

a) FRLS: Mora na comunidade desde antes da criação da Escola Monsenhor Lopes. Ingressou nas primeiras turmas como aluna e manteve uma relação contínua com a comunidade ao longo da vida, mesmo quando precisou se deslocar para outros municípios a fim de concluir os estudos. Fez parte da Associação de Moradores da Comunidade Forte e integra até hoje a comunidade escolar Monsenhor Lopes, tendo assumido inclusive cargos de gestão.

b) FRS: Vive na Comunidade Forte desde antes da implantação da Escola Monsenhor Lopes e é relacionado com a política local. Viu como a escola foi criada e se desenvolveu ao longo do tempo, mas nunca foi aluno ou funcionário dela. Sua relação com a instituição se deve ao fato de seus filhos e netos terem feito parte da comunidade escolar, sendo que alguns ainda a compõem até hoje.

c) HML: Moradora da comunidade desde antes da criação da escola. Foi uma de suas primeiras funcionárias e viu o crescimento da instituição de perto, pois reside nas proximidades, e todos os seus filhos, e até mesmo netos, tiveram alguma relação com a escola (como alunos ou funcionários).

d) PF: Morador que passou por dois momentos educacionais na comunidade: estudou no ensino informal em casas de família e concluiu o ensino fundamental II quando adulto na Escola Monsenhor Lopes. Ficou um tempo fora e, ao voltar, pôde ver os efeitos da presença da escola na comunidade.

e) MSJR: Não é moradora da Comunidade Forte nem foi aluna da Escola Monsenhor Lopes, mas hoje integra a comunidade escolar. Desempenha diversas atividades na escola, inclusive em cargos de gestão. Apesar de não ser moradora da comunidade, possui forte relação com a instituição e é testemunha do papel desta na formação básica dos moradores. 
Esses sujeitos foram selecionados com base em um dos seguintes critérios: 1) moram na comunidade e tiveram ligação com a instituição de ensino em alguma fase da vida (ex-gestores, ex-professores e/ou ex-alunos); 2) moram na comunidade e integram a instituição de ensino; 3) moram na comunidade desde a criação da escola e são testemunhas do desenvolvimento e da relação entre elas ao longo dos anos, apesar de nunca terem feito parte da comunidade escolar; e 4) não moram na comunidade, mas fazem parte da comunidade escolar atualmente. Após a seleção, os sujeitos foram contatados e convidados a participar da pesquisa concedendo entrevistas.

Todos concordaram livremente com a participação e com a utilização do material em publicações (Meihy; Ribeiro, 2011), e tal anuência foi estabelecida por meio da assinatura de um Termo de Consentimento Livre e Esclarecido.

As entrevistas semiestruturadas foram realizadas com o auxílio de um gravador, de forma única, contínua e direta (Marconi; Lakatos, 2003; Meihy; Ribeiro, 2011; Lüdke; André, 2013), e com um roteiro elaborado em sintonia com o objetivo da pesquisa, o qual continha perguntas como: 1) Há quanto tempo você mora na Comunidade Forte? 2) Você se lembra como ocorreu a criação da escola? Você participou desse processo? Se sim, qual e como foi sua contribuição? 3) Você se lembra da inauguração da escola? Como foi? 4) Como eram os alunos atendidos pela escola? 5) Você acha que a escola mudou com o tempo? O que mudou? 6) E a comunidade? Mudou com a chegada da escola? O que mudou? 7) A escola é importante para a comunidade? Por quê? 8) A escola é importante para você? Por quê? 9) Você já teve alguma ligação com a escola? 10) Você estudou na escola? Em qual período? Por quanto tempo? 11) Você trabalhou na escola? Em qual período? Por quanto tempo? 12) No tempo em que você estava na escola, como ela era? Como era a relação entre as pessoas da escola e da comunidade? 13) Havia atividades/conteúdos relacionados com a comunidade? Ou à realidade do campo? 14) O que significou para você estudar/trabalhar nesta escola? 15) A escola já passou por alguma(s) dificuldade(s)? Qual(is)? Como conseguiram superar? A comunidade se envolveu?

O roteiro era flexível, possibilitando sua reorganização e modificação ao longo do processo de gravação, quando o entrevistador julgava necessário, respeitando a fala dos interlocutores sobre a história da escola, em um clima estimulante e de aceitação (Marconi; Lakatos, 2003; Lüdke; André, 2013). As entrevistas cumpriram os requisitos recomendados por Marconi e Lakatos (2003), como validade, relevância, especificidade e clareza. Depois da gravação, as falas dos interlocutores foram transcritas, textualizadas e transcriadas (Meihy; Ribeiro, 2011).

De posse dos dados, obtidos por meio de documentos e entrevistas, foi realizada a análise categorial deles (Creswell, 2008). As categorias consideradas foram: 1) origem, criação, construção e instalação da escola; 2) prédio escolar; 3) professores e outros funcionários; 4) alunos; 5) conteúdos escolares; 6) evolução; 7) atividades entre a escola e a comunidade; 8) organização da escola; e 9) destino profissional de alunos egressos da escola. 
A seleção das categorias tomou por base o texto de Gatti Júnior (2007), e a análise de cada uma foi executada mediante a confrontação dos dados dos documentos com os das entrevistas e vice-versa. Após esse procedimento, os resultados foram apresentados cronologicamente para a construção da linha de tempo da evolução da instituição escolar em conjunto com a comunidade.

\section{Resultados e discussão}

A construção de aspectos da história da Escola Monsenhor Lopes mostrou na sua relação com a Comunidade Forte: 1) a importância da escola para a satisfação da necessidade de escolarização da população local; 2) a interação entre a instituição escolar e outras instituições; 3) a contribuição da escola, contraditoriamente, para a permanência dos sujeitos no campo e para o esvaziamento deste; e 4) a colaboração da escola para o desenvolvimento local.

A história da educação formal da Comunidade Forte se iniciou antes da construção da Escola Monsenhor Lopes. O ensino era realizado em casa de família e só atendia aos filhos dos moradores da comunidade: seja o ensino infantil, na casa de Dona Mariinha de Doutor (in memoriam), ou até mesmo o ensino fundamental I, na casa do senhor Francisco, mais conhecido como Chico Cota. Os locais ainda hoje existem, quase intactos, porém, não mais destinados a essas atividades. Antigamente, tais ensinamentos em casa de família visavam desenvolver habilidades básicas: ler, escrever e resolver cálculos matemáticos simples. Segundo um dos sujeitos, "a escola foi criada por motivo de necessidade do aprendizado aqui no Forte" (JPF, entrevista, 2018).

Assim, apesar dos ensinamentos repassados em casa de família, infere-se que os interlocutores da pesquisa não os consideravam suficientes para suprir suas necessidades - como a de escolarização, que foi satisfeita pela chegada da escola. Nessa perspectiva, Saviani (2013) explica que as instituições escolares surgiram para atender às necessidades humanas permanentes e, por conseguinte, detêm finalidades que se materializam em práticas, incluindo as que são responsáveis pela reprodução de seus agentes internos e pelas condições sociais que a geraram.

De acordo com o Projeto Político-Pedagógico da Escola Monsenhor Lopes, esta iniciou as atividades em 1972; entretanto, não possuía um prédio próprio para seu funcionamento. As atividades de ensino continuaram ocorrendo em casas de família e em uma associação: "primeiro, fizeram uma associação, aí a escola funcionou lá por um bom tempo" (FRS, entrevista, 2018).

Dessa forma, percebe-se uma relação entre a escola, instituição que realiza o trabalho educativo secundário, e outras instituições, como as famílias e as associações, que realizam o trabalho educativo primário (Saviani, 2013). 
O prédio da escola foi construído em 1974, durante a administração do prefeito João Antônio de Sousa Macêdo, em terreno cedido pela família do padre Monsenhor Joaquim de Oliveira Lopes, o qual foi homenageado pela comunidade escolar, que deu seu nome à instituição - Figura 1 (Inhuma, 2017). De acordo com os entrevistados, não houve nenhum ato comemorativo por ocasião da inauguração da escola. A condição da escola era humilde, já que ela era composta por uma única sala para as aulas do ensino fundamental I (que os entrevistados chamaram de ensino fundamental menor).

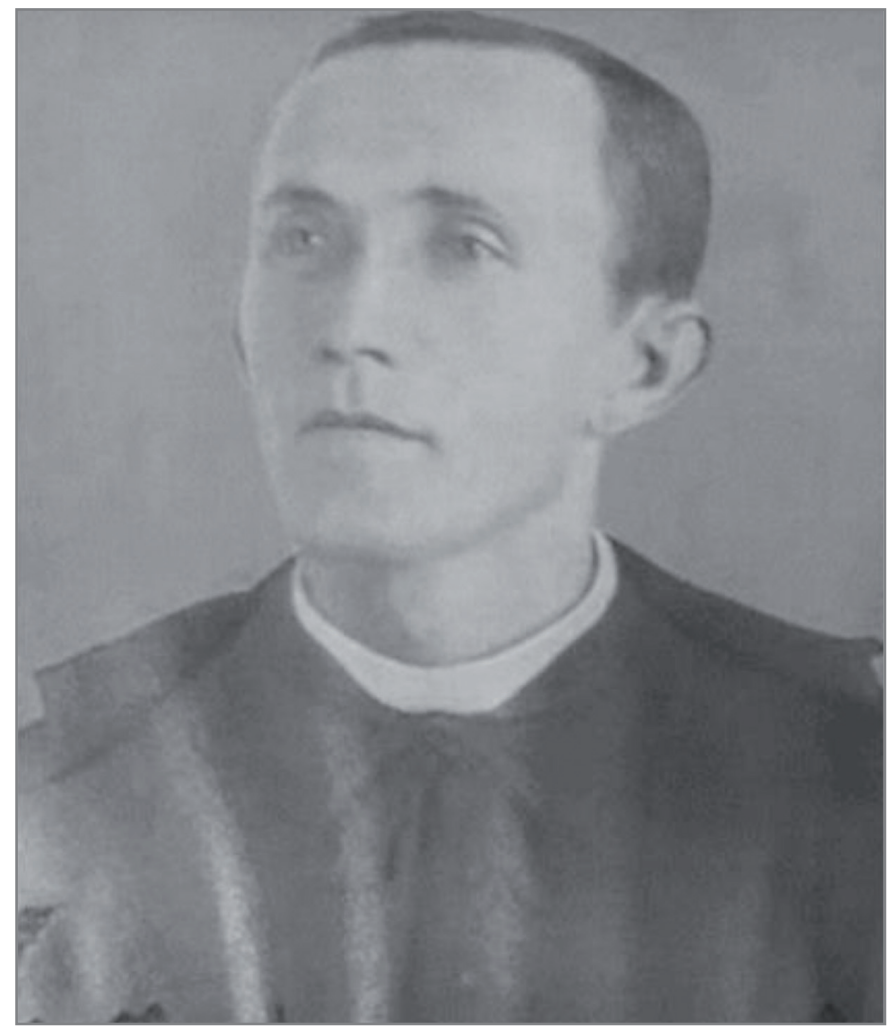

Figura 1 - Padre Monsenhor Joaquim de Oliveira Lopes

Fonte: Arquivo da Escola Municipal Monsenhor Lopes (2018).

A organização da escola teve de se adequar à pequena estrutura física. As turmas eram multisseriadas, e as aulas ocorriam nos turnos da manhã e da tarde, segundo a participante FRLS, que ingressou no corpo docente da instituição em 1984. Assim, a escola era capaz de suprir a demanda de parte dos alunos na época de sua criação, apesar do pequeno espaço de que dispunha.

A escola permaneceu com essa única salinha até 1987, quando houve uma primeira ampliação (Figura 2). Com a construção de três salas de aula, passou a atender um maior número de moradores e a receber alunos de outras localidades, mas a maioria continuava sendo da Comunidade Forte. 


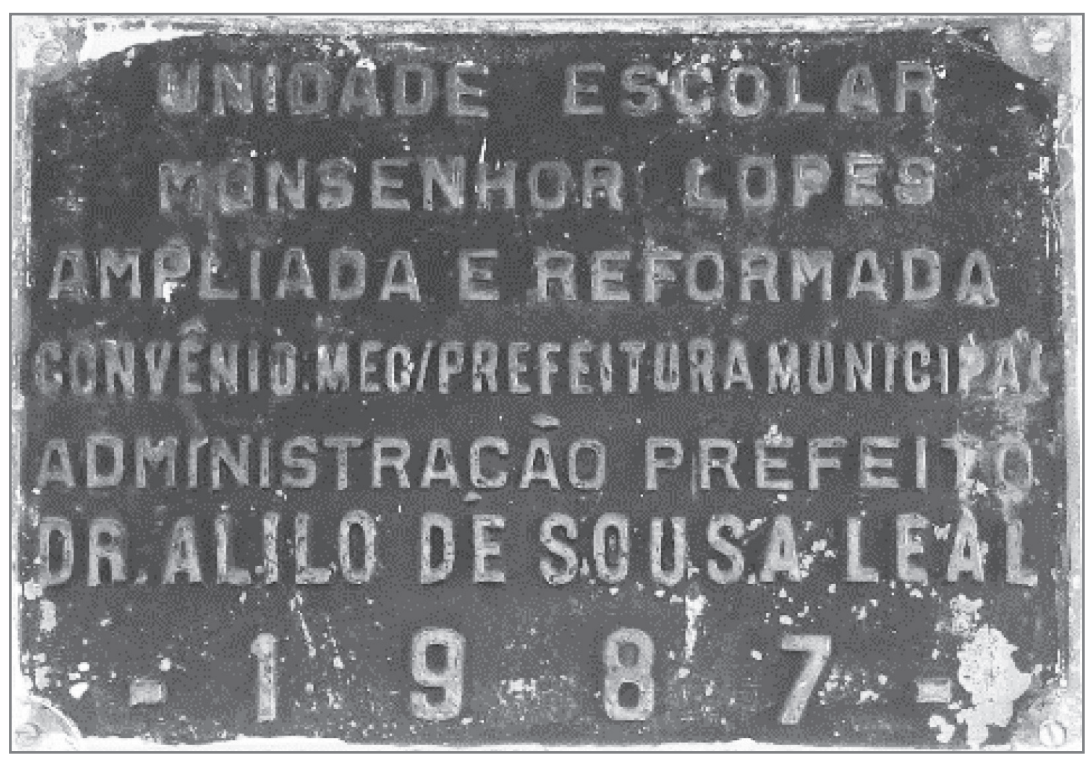

Figura 2 - Placa de ampliação e reforma da Escola Monsenhor Lopes da Comunidade Forte no ano de 1987

Fonte: Foto dos autores.

Entretanto, a escola ainda ofertava somente o ensino fundamental I. Os moradores que desejavam que seus filhos continuassem os estudos tinham de fazer concessões e deixar que eles se deslocassem para cidades vizinhas. "Eu fui para casa de um tio meu, em Inhuma, aí vinha para cá só nos finais de semana. [...] Eu vinha na sexta e voltava na segunda às quatro horas da manhã, porque era para estar às sete na aula" (FRLS, entrevista, 2018).

Isso representava não somente um gasto financeiro para as famílias da comunidade, mas também um desgaste emocional, pois os pais ficavam longe dos filhos durante o período de estudo. Além disso, havia famílias que não tinham condições financeiras para dar suporte aos filhos, inviabilizando a conclusão dos estudos deles na educação básica.

Por isso, a comunidade sofreu um grande impacto em sua estrutura educacional quando em 1998 passou a ser oferecido o ensino fundamental II na Escola Monsenhor Lopes. De acordo com FRLS, a ampliação da oferta de ensino na Comunidade Forte ocorreu não somente pela grande demanda, mas também pelas condições de acesso dadas à comunidade.

Porque aqui [Comunidade Forte] tinha muita criança, muito aluno estudando. Os alunos daqui, começou de mim, caminhando para Inhuma estudar lá, fazer o ensino fundamental maior [ensino fundamental II]. Eu acho que com o número de meninos que foi terminando o quarto ano, que na época a gente chamava de quarto ano, houve a necessidade de colocar o ensino fundamental maior. Aí, como tem essas comunidades vizinhas, eles nuclearam e colocaram aí. O acesso também para vim professor de fora, porque só os daqui não dava para funcionar, porque vem professor da Inhuma para trabalhar aí, para ajudar. (FRLS, entrevista, 2018). 
A oferta de turmas para concluir o ensino fundamental na Escola Monsenhor Lopes representou, ainda, um avanço para a Comunidade Forte, como também para os moradores das comunidades circunvizinhas, que, a partir de então, tiveram a possibilidade de concluir um maior número de etapas educacionais formais sem a necessidade de afastamento da família. Dessa forma, a escola contribuiu tanto para a escolarização da população local como para a sua permanência no campo.

$\mathrm{O}$ atendimento educacional aos moradores da Comunidade Forte e das comunidades vizinhas foi possível não apenas pela ampliação da escola, mas também pelo investimento público em outros setores, como o de transporte: "[...] a escola cresceu, [pois] o poder público investiu pondo ônibus para trazer os alunos mais de longe" (JPF, entrevista, 2018).

De acordo com FRLS, a oferta de transporte para os alunos, e até mesmo para os professores, ocorreu desde o início das atividades do ensino fundamental II, em 1998. Com a possibilidade de transporte, aumentou a quantidade de matriculados. Eram tantos alunos a serem atendidos que a estrutura física da escola mais uma vez não conseguia suprir a demanda.

Nesse ano de implantação do ensino fundamental II, a Escola Monsenhor Lopes passou a usar o prédio da Associação de Produtores Rurais da Região do Forte (Aporf) para dar suporte às atividades educacionais: "[...] sempre a gente usava umas salinhas lá para levar turma porque não cabia na outra [neste caso, no prédio da escola]". (FLRS, entrevista, 2018).

Ainda hoje, funcionam algumas salas de aula e a biblioteca da escola nesse prédio, que a entrevistada denominou "anexo". A utilização desse segundo espaço se deu de maneira informal, pois não houve nenhuma reunião com os moradores ou produtores, até mesmo porque a associação não desenvolvia nenhuma atividade no prédio. Mais uma vez, vê-se a relação entre a escola e outras instâncias sociais.

Apesar do aumento no número de alunos e de comunidades atendidas, a Escola Monsenhor Lopes continuava trabalhando no limite de sua capacidade física, mesmo usando o prédio da associação e multisseriando turmas. Somente depois de mais de uma década da implantação do ensino fundamental II, a escola passou por uma série de reformas e ampliações. Entre 2010 e 2015, duas salas de aulas foram construídas e implantou-se um núcleo de informática, entre outros reparos para oferecer melhores condições de trabalho e ensino (Inhuma, 2017).

Atualmente, a escola conta com seis salas de aula e um conjunto de áreas para suporte organizacional, pedagógico e de gestão (diretoria, núcleo de informática, refeitório, almoxarifado, cantina, despensa e banheiros). Mesmo assim, ainda precisa de mais duas salas de aula para suprir a demanda, uma biblioteca (que funciona até hoje no "anexo"), um auditório para a realização de eventos, uma sala de coordenação pedagógica e de professores e a conclusão da quadra de esportes, que está em construção há mais de dois anos (Inhuma, 2017).

Hoje, a Escola Monsenhor Lopes oferta turmas do ensino infantil ao ensino fundamental (I e II), da creche ao $9^{\circ}$ ano. Ainda há turmas multisseriadas, porém, em menor número que antes e se restringem ao ensino infantil. O motivo de existirem essas salas multisseriadas seria 
a baixa demanda de alunos para algumas séries e não apenas a falta de espaço físico.

As mudanças ao longo dos anos na Escola Monsenhor Lopes não se referem somente à estrutura física e às modalidades de ensino, mas também à comunidade escolar, tanto o corpo docente quanto o discente: "[...] os primeiros professores eram moradores da região, que não possuíam nenhuma formação pedagógica, apenas tinham domínio da leitura, de cálculos matemáticos e conhecimentos gerais" (MSJR, entrevista, 2018).

Esses professores ingressavam na escola via indicação política.

[...] me deram uma sala de aula por indicação. Naquela época ninguém fazia concurso. Então, como eu já tinha o magistério, me passaram para a sala de aula, aí comecei a trabalhar alfabetizando crianças. [...] Naquele tempo eles só faziam indicar, questão partidária mesmo. (FRLS, entrevista, 2018).

Não obstante o advento da Constituição Federal de 1988 e da legislação pertinente ao ingresso de professores no serviço público, houve apenas um concurso, que ocorreu há cerca de 13 anos, para ingresso de novos professores. Entretanto, mesmo após o concurso, a maioria do corpo docente da escola no momento é composta por pessoas da comunidade. "A maioria é daqui [da Comunidade Forte] e só não já fechou com os professores daqui porque quando fizeram o concurso esses meninos não tinham terminado [o ensino superior] ainda" (FRLS, entrevista, 2018).

Houve uma mudança no perfil do quadro docente da escola: antigamente, a maioria dos professores era de fora da Comunidade Forte, principalmente da sede do município de Inhuma; no presente, a maioria dos professores é da própria comunidade. Dessa forma, a Escola Monsenhor Lopes tem contribuído para a criação de postos de trabalho e, por conseguinte, para a permanência da população camponesa.

Além disso, a nomeação de professores da comunidade tem colaborado para a melhoria da qualidade do ensino, um dos princípios da Educação do Campo (Brasil. MEC, 2007). O fato de os primeiros professores não serem da comunidade comprometia o ensino, visto que as aulas ocorriam de forma esporádica: "[...] tinha uma parente de papai que deu aula para mim aqui, ela vinha da Inhuma. O que que acontecia? As aulas, se tivesse dois, três dias da semana, tinha muito" (FRLS, entrevista, 2018).

Ademais, o ensino não possuía nenhuma relação com a Comunidade Forte nem com o campo.

\footnotetext{
No tempo que eu estudei aqui, os professores não tinham aquela preocupação das atividades relacionadas com o campo, porque cada aluno já trazia esses conhecimentos de casa. Porque além da gente estudar, também trabalhava em casa nos serviços domésticos e na roça com os nossos pais. (FRLS, entrevista, 2018).
}

Assim, o ensino não era contextualizado, isto é, não partia da realidade dos alunos do campo e/ou não tinha ligação com o cotidiano deles no sentido de transformá-lo, aproximando-se mais do paradigma da Educação Rural (Ribeiro, 2013). 
O perfil dos alunos da Escola Monsenhor Lopes também mudou ao longo dos anos. Antes, logo no início da implantação da escola, os alunos trabalhavam na agricultura familiar, auxiliando os pais nos serviços da roça; entretanto, hoje, dificilmente algum aluno desenvolve esse trabalho. Atualmente, os alunos "[...] não vivem mais trabalhando, dificilmente tem um para viver trabalhando. Eles já estão "caindo na real", que tem que estudar" (FRLS, entrevista, 2018).

Esse relato indica uma valorização da educação, na qual o homem do campo tem uma perspectiva para a melhoria de vida. No entanto, o ensino ofertado pela Escola Monsenhor Lopes é considerado uma forma de preparação para os alunos ingressarem no mercado de trabalho ou prosseguirem os estudos até a educação superior. Percebe-se que ainda persiste, contraditoriamente, um distanciamento do processo de escolarização com o trabalho no campo, que integre teoria e prática em uma práxis que valorize a realidade e os saberes locais (Ribeiro, 2013). A Educação do Campo se faz presente não apenas na contextualização do ensino, mas também nas finalidades que norteiam as atividades da escola e de seus agentes. Portanto, problematiza-se se esse ensino propedêutico não contribuiria para um afastamento futuro dos alunos de sua comunidade. A preocupação com o ingresso dos alunos na educação superior e na carreira pública influencia o ensino ofertado pela escola, que continua com características da Educação Rural.

Uma coisa que eu nunca gostei aqui, que mudou, foi essa questão de
campo. Assim, no maior [ensino fundamental II] não existiu isso não,
mas no menor [ensino fundamental I] tem o livro do campo e o livro
da cidade, e eu não concordei muito com isso não. Eu estou fazendo
porque eu não dou jeito. Porque quando vem os vestibulares da vida,
os Enem da vida, os concursos da vida, não vem baseado em campo
não. Tão seguindo o livro, só que eu não sigo não. As minhas aulas são
diferentes. Eu ainda vou lá nas escolinhas particulares, procuro livro
bom, porque você chega bem aqui em um interior desse tem internet,
tem tudo, então para que essa diferença aí? (FLRS, entrevista, 2018).

A presença da Educação Rural é reforçada no planejamento da Escola Monsenhor Lopes, realizado bimestralmente na sede do município de Inhuma, com os professores da rede municipal de ensino, independentemente de serem da cidade ou do campo. Tal fato pode comprometer a ideia e a preparação de um ensino voltado para o campo.

Nesse sentido, observa-se também um distanciamento da Educação do Campo por meio da análise do Projeto Político-Pedagógico da Escola Monsenhor Lopes, que não possui nas referências nenhuma bibliografia que aborde essa modalidade nem documentos norteadores, como as Diretrizes Operacionais para a Educação Básica nas Escolas do Campo (Brasil. MEC. CNE, Ceb, 2002).

Apesar disso, a existência da Escola Monsenhor Lopes é considerada primordial pelas pessoas da Comunidade Forte.

[...] foi na escola que todos os meus filhos também se instruíram para uma vida digna. (FRLS, entrevista, 2018). 
[A escola é importante para a comunidade] porque é ensinamento.

(FRS, entrevista, 2018).

[A escola é importante para a comunidade] porque aprende. [...] estou feliz porque estou vendo eles aprendendo. (HML, entrevista, 2018).

[A escola é fundamental na Comunidade Forte] porque o ensino, a educação está em primeiro lugar. (JPF, entrevista, 2018).

O reconhecimento da relevância da educação para o desenvolvimento cultural, financeiro e social dos moradores da Comunidade Forte ocorreu justamente em virtude da existência da Escola Monsenhor Lopes. Nesse aspecto, JPF relatou a importância da escola para o desenvolvimento de pessoas do campo para o campo: "[...] porque dali onde sai algumas pessoas que hoje são formadas, já tem seus cursos que é em volta dos agricultores dali" (JPF, entrevista, 2018).

Além disso, a escola também contribuiu para manter os moradores da comunidade ao dar suporte financeiro e, assim, impedir que eles migrassem para a cidade à procura de trabalho. "Aquela escola é minha vida, eu trabalhei muito ali. Mas foi minha salvação, porque foi de lá onde adquiri meu sustento, me mantive até hoje. Agradeço a Deus todo dia por ela" (JPF, entrevista, 2018).

A importância da escola para os moradores da Comunidade Forte vai além da relação profissional ou de formação, sendo até mesmo de ordem emocional, uma relação afetiva: "[...] hoje essa Escola para mim é como se fosse um membro de minha família, ou seja, um pedacinho de mim" (FRLS, entrevista, 2018).

Ao considerarmos os princípios da Educação do Campo, é possível afirmar que a relação com a comunidade é um ponto crucial para a delimitação e a caracterização do ensino campesino (Brasil. MEC, 2007). Espera-se com isso a ampliação do acesso à escola, sendo que tal acesso não deve ser somente aos que necessitam de formação, mas também aos que podem colaborar com ela, como familiares, organizações e movimentos populares (Kolling; Nery; Molina, 1999).

Apesar das conquistas realizadas, a relação da Comunidade Forte com a Escola Monsenhor Lopes precisa ser intensificada. A interação da comunidade, representada por pais e responsáveis pelos alunos, com a escola parece ser esporádica e se limita a eventos e reuniões, o que não deveria ocorrer, dada a proximidade da escola com a casa dos moradores. Assim, é possível que, mesmo com os avanços, a Escola Monsenhor Lopes enfrente dificuldades para se consolidar como uma escola do campo, porque a participação da Comunidade Forte se restringe ao acompanhamento do rendimento escolar e aos eventos.

Em conclusão, considerando a localização da escola e a quantidade de comunidades atendidas, afirmamos que ela é de suma importância para a formação, tanto do ponto de vista educacional como social, dos moradores da zona rural do município de Inhuma, como as pessoas da Comunidade Forte. 


\section{Considerações finais}

A Escola Monsenhor Lopes foi fundada há quase 50 anos e é a principal responsável pela escolarização não somente dos moradores da Comunidade Forte, mas também de pessoas oriundas de comunidades circunvizinhas. Este trabalho sobre a construção de aspectos da história da Escola Monsenhor Lopes mostrou: 1) a importância da escola para a satisfação da necessidade de escolarização da população local; 2) a interação entre a instituição escolar e outras instituições; 3) a contribuição da escola, contraditoriamente, para a permanência dos sujeitos no campo e para o esvaziamento deste; e 4) a colaboração da escola para o desenvolvimento local. É imprescindível ressaltar a força de vontade e o anseio por uma vida melhor dos sujeitos do campo, pois, mesmo com as dificuldades no sistema educacional encontradas ao longo dos anos, eles não mediam esforços para prover a escolarização dos filhos.

Apesar da contribuição e do papel fundamental que a escola teve na formação básica das pessoas da Comunidade Forte, somente em 1987, 15 anos depois de sua fundação, ela passou pela primeira reforma e ampliação. Desde então, a escola cresceu, não apenas em estrutura física, mas também em relevância para a formação básica dos sujeitos do campo do município de Inhuma, pois atualmente atende à Comunidade Forte e a dez localidades circunvizinhas, ofertando turmas de ensino infantil e fundamental (desde a creche até o $9^{\circ}$ ano) e com a maioria do corpo docente composto por pessoas da própria comunidade.

Constatou-se que a Escola Municipal Monsenhor Lopes é extremamente importante e indispensável no processo de desenvolvimento e crescimento da Comunidade Forte e que ambas caminham juntas, sendo que a formação de uma depende da outra. A escola é constituída pela comunidade, cujos indivíduos foram preparados pela instituição para a vivência na sociedade, contribuindo, assim, para seu desenvolvimento. Porém, a comunidade não deve apenas prover alunos para a escola, mas também participar diretamente de sua gestão e organização pedagógica, buscando maior integração da realidade do campo com o ensino oferecido.

Entre os entrevistados, é perceptível o entusiasmo em resgatar suas memórias e contribuir para a construção de sua própria história. A utilização da memória dos sujeitos do campo em um estudo tão próximo à realidade e à história deles produziu, mesmo que indiretamente, uma valorização de sua identidade como moradores da Comunidade Forte. Também os provocou a refletir sobre o tipo de educação que é ofertado e os impactos do ensino na vida e no desenvolvimento das pessoas da comunidade. Com isso, espera-se que este trabalho tenha despertado o interesse nesses sujeitos para se integrarem mais à escola, como disseminadores, contribuindo, ainda que seja com pouco, para a valorização dela e da comunidade e para o reconhecimento dos sujeitos do campo. Além disso, este estudo poderá despertar novos olhares sobre essa comunidade, sua educação e seus traços históricos e, consequentemente, cooperar com pesquisas relacionadas às escolas do campo e às comunidades rurais. 


\section{Referências}

ANDRADE, F. A. G.; TOLEDO, C. A. de. A. História da implantação da Escola Rural de Xaxim (1952-1961) no contexto da escolarização do oeste paranaense. Quaestio, Sorocaba, v. 19, n. 1, p. 47-68, abr. 2017.

BECK, K. M. K. Vivências e memórias: a cultura escolar da Escola Rural Mista Municipal Santo Antonio em Tangará da Serra, MT (19651983). 2015. 160 f. Dissertação (Mestrado em Educação) - Instituto de Educação, Programa de Pós-Graduação em Educação, Universidade Federal de Mato Grosso, Cuiabá, 2015.

BRASIL. Lei no 9.394, de 20 de dezembro de 1996. Estabelece as diretrizes e bases da educação nacional. Diário Oficial da União, Brasília, DF, 23 dez. 1996. Seção 1, p. 27833.

BRASIL. Ministério da Educação (MEC). Diretrizes Curriculares Nacionais Gerais da Educação Básica. Brasília: MEC, 2013.

BRASIL. Ministério da Educação (MEC). Educação do Campo: diferenças mudando paradigmas. Brasília: MEC, 2007. (Cadernos Secad, 2).

Disponível em: <http://portal.mec.gov.br/secad/arquivos/pdf/ educacaocampo.pdf >. Acesso em: 8 ago. 2019.

BRASIL. Ministério da Educação (MEC). Referências para uma Política Nacional de Educação do Campo: caderno de subsídios. Brasília: MEC, 2003. Disponível em: <http://www.gepec.ufscar.br/publicacoes/ educacao-no-campo/referencias-para-uma-politica-nacional-de-educacao. pdf/at_download/file>. Acesso em: 8 ago. 2019.

BRASIL. Ministério da Educação (MEC). Conselho Nacional de Educação (CNE). Câmara da Educação Básica (CEB). Resolução no ${ }^{\circ}$, de 3 de abril de 2002. Institui Diretrizes Operacionais para a Educação Básica nas Escolas do Campo. Diário Oficial da União, Brasília, DF, 9 abr. 2002. Seção 1, p. 32.

BUFFA, E.; NOSELLA, P. As pesquisas sobre instituições escolares: balanço crítico. In: LOMBARDI, J. C.; DERMEVAL, S. (Org.). Navegando na história da educação brasileira. Campinas: Autores Associados, 2006. p. 5074-5086.

CALDART, R. S. Por uma educação do campo: traços de uma identidade em construção. In: ARROYO, M. G.; CALDART, R. S.; MOLINA, M. C. (Org.). Por uma educação do campo. 5. ed. Petrópolis, RJ: Vozes, 2011. p. 147-160.

CALDART, R. S. Educação do campo. In: CALDART, R. S. et al. (Org.). Dicionário da Educação do Campo. 2. ed. Rio de Janeiro: Escola Politécnica de Saúde Joaquim Venâncio, 2012. p. 257-265. 
CRESWELL, J. W. Educational research: planning, conducting, and evaluating quantitative and qualitative research. 3. ed. Columbus: Pearson, 2008.

FERNANDES, B. M. Educação do campo e território camponês no Brasil. In: SANTOS, C. A. (Org.). Por uma educação do campo: campo - políticas públicas - educação. Brasília: Ministério do Desenvolvimento Agrário, 2008. p. 39-66. (Coleção Por uma Educação do Campo, 7).

GATTI JÚNIOR, D. História e historiografia das instituições escolares: percursos de pesquisa e questões teórico-metodológicas. Revista Educação em Questão, Natal, v. 28, n. 14, p. 172-191, jan./jun. 2007.

GATTI JÚNIOR, D.; GATTI, G. C. V. A história das instituições escolares em revista: fundamentos conceituais, historiografia e aspectos de investigação recente. Educativa, Goiânia, v. 17, n. 2, p. 327-359, jul./dez. 2015.

INHUMA (Município). Secretaria Municipal de Educação, Cultura e Desportos. Escola Municipal Monsenhor Lopes. Projeto Político Pedagógico. Inhuma: Secretaria Municipal de Educação, Cultura e Desportos de Inhuma, 2017.

JESUS, N. O. C. Escola Municipal Rural Água Mansa Coqueiros em Rio Verde: história e memória. 2016. 263 f. Dissertação (Mestrado em Educação) - Escola de Formação de Professores e Humanidades, Pontifícia Universidade Católica de Goiás, Goiânia, 2016.

KOLLING, E. J.; NERY, I.; MOLINA, M. C. Por uma educação básica do campo. Brasília: Articulação Nacional por uma Educação do Campo, 1999. (Coleção Por uma Educação Básica do Campo; 1).

LIBANIO, R.; NOGUEIRA, A. S. C. Pesquisa histórica das instituições escolares: uma nova perspectiva da Educação. In: PARANÁ. Secretaria de Estado da Educação. Os desafios da escola pública paranaense na perspectiva do professor PDE: produções didático-pedagógicas. Curitiba, 2014. p. 1-16. (Cadernos PDE, 2). Disponível em: <http://www. diaadiaeducacao.pr.gov.br/portals/cadernospde/pdebusca/producoes pde/2014/2014_uenp_ped_pdp_rute_libanio.pdf >. Acesso em: 8 ago. 2019.

LÜDKE, M.; ANDRÉ, M. E. D. A. Pesquisa em educação: abordagens qualitativas. 2. ed. Rio de Janeiro: Editora Pedagógica e Universitária, 2013.

MAGALHÃES, J. Um apontamento metodológico sobre a história das instituições educativas. In: SOUSA, C. P.; CATANI, D. B. (Org.). Práticas educativas, culturas escolares, profissão docente. São Paulo: Escrituras, 1998. 
MARCONI, M. A.; LAKATOS, E. M. Fundamentos de metodologia científica. 5. ed. São Paulo: Atlas, 2003.

MEIHY, J. C. S. B.; RIBEIRO, S. L. S. Guia prático de história oral: para empresas, universidades, comunidades, famílias. São Paulo: Contexto, 2011.

MOLINA, M. C.; JESUS, S. M. S. A. (Org.). Contribuições para a construção de um projeto de Educação do Campo. Brasília: Articulação Nacional Por Uma Educação do Campo, 2004. (Coleção Por uma Educação do Campo, 5).

RIBEIRO, M. Movimento camponês, trabalho e educação: liberdade, autonomia, emancipação: princípios/fins da formação humana. 2. ed. São Paulo: Expressão Popular, 2013.

SANFELICE, J. L. História e historiografia de instituições escolares. Revista HISTEDBR On-line, Campinas, v. 9, n. 35, p. 192-200, set. 2009.

SAVIANI, D. Aberturas para a história da educação: do debate teóricometodológico no campo da história ao debate sobre a construção do sistema nacional de educação no Brasil. Campinas: Autores Associados, 2013.

TEIXEIRA, B. B. Comunidade escolar. In: OLIVEIRA, D. A.; DUARTE, A. M. C.; VIEIRA, L. M. F. (Org.). Dicionário: trabalho, profissão e condição docente. Belo Horizonte: Faculdade de Educação da Universidade Federal de Minas Gerais, 2010. CD-ROM.

Recebido em 10 de dezembro de 2019.

Aprovado em 11 de dezembro de 2020. 